\title{
Vitamin status and cognitive function in a long-term care population Lina Paulionis ${ }^{1}$, Sheri-Lynn Kane ${ }^{2}$ and Kelly A Meckling*1
}

Address: ${ }^{1}$ Department of Human Health and Nutritional Sciences, University of Guelph, Guelph, Ontario, Canada and ${ }^{2}$ St. Joseph's Hospital and Home, Guelph, Ontario, Canada

Email: Lina Paulionis - linapaulionis@hotmail.com; Sheri-Lynn Kane - skane@golden.net; Kelly A Meckling* - kmecklin@uoguelph.ca

* Corresponding author

Published: 13 December 2005

BMC Geriatrics 2005, 5:16 doi:10.1/86/147|-23/8-5-16
Received: 17 March 2005

Accepted: 13 December 2005

This article is available from: http://www.biomedcentral.com/l47/-23/8/5/16

(c) 2005 Paulionis et al; licensee BioMed Central Ltd.

This is an Open Access article distributed under the terms of the Creative Commons Attribution License (http://creativecommons.org/licenses/by/2.0), which permits unrestricted use, distribution, and reproduction in any medium, provided the original work is properly cited.

\begin{abstract}
Background: Ageing can be associated with poor dietary intake, reduced nutrient absorption, and less efficient utilization of nutrients. Loss of memory and related cognitive function are also common among older persons. This study aimed to measure the prevalence of inadequate vitamin status among long-term care patients and determine if an association exists between vitamin status and each of three variables; cognitive function, vitamin supplementation, and medications which alter gastric acid levels.
\end{abstract}

Methods: Seventy-five patients in a long-term care hospital in Guelph, Ontario were recruited to a cross-sectional study. 47 were female and the mean age was $80.7(+/-1 I .5)$ years, ranging from 48 to 100 years. Blood was used to measure levels of vitamins BI2 (cobalamin), B6 (pyridoxal-5'phosphate/PLP), erythrocyte folate, vitamin B3 (niacin) and homocysteine (Hcy). The Standardized Mini-Mental State Examination (SMMSE) was administered to measure cognitive function. A list of medications and vitamin supplementation for each patient was provided by the pharmacy.

Results: The prevalence of low vitamin (BI2, B6, erythrocyte folate, niacin) or high metabolite (homocysteine) levels among 75 patients were as follows: BI2 <I48 pmol/L in 5/75 (6.7\%); BI2 between I 48 and $22 \mathrm{I} \mathrm{pmol} / \mathrm{L}$ in 26/75 (34.7\%); B6 $\leq 30 \mathrm{nmol} / \mathrm{L}$ in $4 / 75$ (5.3\%); erythrocyte folate $<370 \mathrm{nmol} / \mathrm{L}$ in I/75 (I.3\%); niacin ratio $\leq \mathrm{I}$ in 20/75 (26.7\%); homocysteine $>13.3 \mu \mathrm{mol} / \mathrm{L}$ in $3 \mathrm{I} / 75$ (4I.3\%). There was no significant difference among residents grouped into marked $(n=44)$, mild $(n=14)$, or normal $(n=9)$ cognitive function when evaluating the effect of vitamin status. There were no significant differences in mean BI 2 and homocysteine levels between users and non-users of drug therapy (Losec, Zantac, or Axid). Compared to vitamin supplement non-users, supplemented residents had significantly higher mean BI2 $(p<0.000 \mathrm{I})$ and erythrocyte folate $(p<$ $0.05)$ concentrations and significantly lower mean homocysteine $(p<0.01)$ levels; 229.1 versus $423.6 \mathrm{pmol} / \mathrm{L}$ for B I 2, 882.9 versus $1043.6 \mathrm{nmol} / \mathrm{L}$ for erythrocyte folate and I 4.4 versus $12.0 \mu \mathrm{mol} /$ $L$ for homocysteine.

Conclusion: Given the prevalence data on vitamin status in this sample population, the possible benefits of vitamin supplementation should be considered in clinical intervention studies using these populations of elderly. 


\section{Background}

Among independently living, normally aging study populations, evidence exists to support an association between more optimal nutriture (measured by dietary intake or blood parameters) and better performance on cognitive tests [1-3]. Some researchers have suggested that even marginal nutritional status may affect cognitive function [4]. The findings in a six-year follow-up study by La Rue et al [3] showed significant associations between past and concurrent nutrient intakes and better cognitive performance. This would suggest a benefit of a more global diet throughout adulthood.

The role of specific B vitamins in brain related disorders vitamin $B_{12}$ or niacin in severe cases of cognitive dysfunction [5], folate in depression [6], and vitamin $B_{6}$ in convulsive seizures [7] - has also prompted research on micronutrients and their potential to mitigate cognitive deterioration. Discounting niacin, which has received less attention from researchers, relations of these B vitamins and their metabolic derivative homocysteine (Hcy) to cognitive performance have been demonstrated [8]. Compared to control populations, there also appears to be significantly elevated Hcy $[9,10]$ and low $B_{12}$ and folate levels among Alzheimer disease patients [9].

Levels of vitamin $B_{12}[11,12]$, folate [11] and vitamin $B_{6}$ $[13,14]$ are often insufficient among older persons. For vitamin $B_{12}$ and folate, reduced gastric acid secretion (hypochlorhydria or achlorhydria) from atrophic gastritis [15] or the use of medications [16] impair absorption of these vitamins. For vitamin $\mathrm{B}_{6}$ it appears the problem is not an absorptive one, but rather one of cellular uptake or metabolism of the vitamin [17]. Questions have been raised as to whether or not circulating serum vitamin levels are a true measure of deficiency [18]. For this reason, Hcy has been touted as a more reliable measure of deficiency since its metabolism is dependent on functional vitamin $B_{12}$, folate and vitamin $B_{6}$ in tissue. Its usefulness is however limited by genetic, demographic, lifestyle, and pathophysiological factors, all capable of elevating Hcy [19].

Vitamin insufficiencies have been implicated in neurodegenerative disorders and vascular disease; hyperhomocysteinemia already confirmed as an independent risk factor in the latter [20]. With an ever-increasing aging population in North America, ensuring adequate nutriture carries many advantages related to longevity of life and savings in public health resources. To better understand the nutritional needs of institutionalized older persons in Ontario, our study evaluated vitamin status $\left(\mathrm{B}_{12}\right.$, folate, $B_{6}$, niacin, Hcy) and its association with cognitive function, vitamin supplementation and medication use.

\section{Methods \\ Ethics and subject recruitment}

Ethics approval was granted by the Research Ethics Board of St. Joseph's Hospital (Hamilton, ON). Information and consent letters outlining the study's objectives and details of subject involvement were sent out to families of residents. St. Joseph's Hospital and Home, located in Guelph Ontario, provides long-term high level care, rehabilitation and out-reach services typical of Type II and III facilities across Canada. Medical and nursing staff gave approval for more cognizant residents to individually consent (verbal or written). Family consent was otherwise required for less independent residents with more severe cognitive impairments. Of the total 127 long-term care residents, 8 residents died during subject recruitment and 44 did not grant consent, because they or their guardians were worried about blood work, guardians thought the resident may be upset by the mini-mental state exam, or were too frail to participate. There were no overall differences between the range of illnesses in participating and nonparticipating subjects. Seventy-five residents ( 47 females, 28 males) consented. All 75 participated in the blood work and 67 out of 75 residents partook in the Standardized Mini-Mental State Examination (SMMSE). There were no exclusion criteria for subject involvement given the cross-sectional nature of the study. Of the 75 subjects, 46 had been diagnosed with dementia. Twenty-nine subjects, although not being diagnosed with dementia had several other diagnoses that could affect cognitive function. These included: Parkinson's disease, mental retardation, multiple sclerosis, head injury, transient ischemia attack, hemiplegia, hemiparesis, cerebrovascular attack and seizures. The average age of the subjects was $80.7 \mathrm{yrs}$ (range 48-100) with no difference between males and females. The average duration of long-term care was 1.85 yrs (range 0.1-9) and was not different between males and females.

\section{Medical and nutritional data}

Medical charts were used to collect information on age and gender. A list of medications and vitamin supplementation (oral, intramuscular) was provided by the pharmacy. Medications of interest were proton pump inhibitors (PPIs) (i.e. Losec ${ }^{\circledR}$ ) and histamine-2 receptor antagonists (H2-blockers) (i.e. Zantac ${ }^{\circledast}$ or Axid ${ }^{\circledast}$ ). A multivitamin (5000 I.U. vitamin A, $3 \mathrm{mg}$ vitamin $B_{1}, 2.5 \mathrm{mg}$ vitamin $B_{2}, 20 \mathrm{mg}$ niacinamide, $1 \mathrm{mg}$ vitamin $\mathrm{B}_{6}, 3 \mu \mathrm{g}$ vitamin $B_{12}, 50 \mathrm{mg}$ vitamin $C, 400$ I.U. vitamin $\left.D\right)$ and $a$ $1000 \mu \mathrm{g}$ intramuscular vitamin $\mathrm{B}_{12}$ injection were considered for vitamin supplementation. Of the 28 subjects using vitamin supplements, 10 had $B_{12}$ injections and 18 took the standard oral multivitamin supplement. Supplement prescriptions were provided by each subject's family doctor and not based on any pre-determined deficiency symptoms. There were no differences between users/non- 
users of drugs or supplements according to age or gender. Because incidence of specific disease were low for all categories differences in frequency between users and nonusers could not be determined.

\section{Cognitive status}

The SMMSE was used to assess the degree of cognitive impairment. To decrease methodological faults and assure methodological reliability, the administrator: 1) Reviewed the SMMSE procedure and grading system outlined in a short booklet and video, 2) Observed a geriatrician conduct the SMMSE on residents not part of the study and 3) Was supervised when conducting the SMMSE on residents not part of the study. The SMMSE was administered on 67 of the 75 residents that gave consent for study participation. Subjects were categorized according to the following: marked cognitive impairment (scores between 0 and 20); mild cognitive impairment (scores between 21 and 25); and normal (scores between 26 and 30). Residents that participated but were mute and/or unresponsive to the administrator's cues received a score of zero out of 30 [21].

\section{Blood collection and analysis}

Blood was collected after an overnight fast at a time when routine annual creatinine measurements would have to be taken. Five tubes of blood were drawn from each resident: One $5 \mathrm{ml} \mathrm{SST} \mathrm{tube} \mathrm{for} \mathrm{creatinine} \mathrm{and} \mathrm{serum} \mathrm{B}_{12}$, one $2 \mathrm{ml}$ EDTA tube for erythrocyte folate, two $5 \mathrm{ml}$ EDTA tubes for Hcy and vitamin $\mathrm{B}_{6}$, and one $6 \mathrm{ml}$ heparin tube for niacin and methylmalonic acid (analysis incomplete). Blood samples were immediately placed on ice. Blood was collected from six to ten subjects per day over a period of nine days. Within 1.5 hours of blood collection, $100 \mu \mathrm{L}$ of whole blood from the heparin tube was transferred to a $1.5 \mathrm{ml}$ eppendorf tube; EDTA tubes for Hcy and $\mathrm{B}_{6}$ analysis were immediately centrifuged and the plasma transferred into clean tubes. Hcy samples were stored at $-20^{\circ} \mathrm{C}$, niacin and $\mathrm{B}_{6}$ samples at $-70^{\circ} \mathrm{C}$. Blood samples for creatinine, serum $B_{12}$ and erythrocyte folate analysis were immediately transported to the laboratory for analysis.

Chemiluminescent immunoassays were used for the quantitative determination of vitamin $\mathrm{B}_{12}$ and erythrocyte folate (Guelph General Hospital Laboratory Services, Guelph, ON, Canada). It was decided to measure erythrocyte folate rather than serum folate since the former reflects tissue stores of folate and is a more stable marker of folate status. Serum folate is more affected by recent changes in dietary intake $[2,21]$. The coefficients of variation for cobalamin were as follows: mean value $65 \mathrm{pmol} /$ $\mathrm{L}$ (5\% CV within run, 8.5\% CV for total precision); mean value $276 \mathrm{pmol} / \mathrm{L}$ ( $4.8 \% \mathrm{CV}$ within run, $6.6 \% \mathrm{CV}$ for total precision); mean value $572 \mathrm{pmol} / \mathrm{L}$ (6.9\% CV within run, $7.5 \%$ CV for total precision); mean value $719 \mathrm{pmol} / \mathrm{L}$
(11.4\% CV within run, $11.4 \% \mathrm{CV}$ for total precision). The coefficients of variation for erythrocyte folate were as follows: mean value $292 \mathrm{nmol} / \mathrm{L}$ (2.5\% CV within run, $7.8 \%$ $\mathrm{CV}$ for total precision); mean value $884 \mathrm{nmol} / \mathrm{L}(2.3 \% \mathrm{CV}$ within run, 5.9\% CV for total precision); mean value 1375 $\mathrm{nmol} / \mathrm{L}$ (3.1\% CV within run, 5.7\% CV for total precision); mean value $1948 \mathrm{nmol} / \mathrm{L}$ (2.4\% CV within run, $5.8 \% \mathrm{CV}$ for total precision).

Creatinine blood samples were sent to Guelph General Hospital Laboratory, Guelph, ON, Canada (3\% CV within run, $4.5 \% \mathrm{CV}$ for total precision). Creatinine combined with picric acid to produce a colored creatinine-picrate complex. The differential absorbance measured (520 nm and $560 \mathrm{~nm}$ ) was proportional to creatinine concentration. Creatinine clearance was calculated using the formula of Cockcroft and Gault: [(140age (years))*weight $(\mathrm{kg})] /[$ serum creatinine $(\mu \mathrm{mol} /$ $\mathrm{L})^{*} 0.81$ ]. For women, this value was multiplied by 0.85 .

Vitamin $B_{6}$ blood samples were sent on dry ice to St. Joseph's Health Centre, Reference Testing Centre, London, ON, Canada (3.5\% CV within run, $4.8 \% \mathrm{CV}$ between runs). Pyridoxal-5'-phosphate (PLP) was detected by HPLC ( $\mathrm{C}_{18}$ ODS reversed-phase column) and fluorometric detection (325 nm excitation, $400 \mathrm{~nm}$ emission) after post column derivatisation with $\mathrm{pH} 7.5$ phosphate buffer containing $1 \mathrm{~g} / \mathrm{L}$ sodium sulphite. Pyridoxal-5'-phosphate ( 0 to $200 \mathrm{nmol} / \mathrm{L}$ ) were used as calibrators. Pyridoxamine 5 '-phosphate was used as an internal standard.

Hcy blood samples were sent on dry ice to the Lab Reference Centre, Hamilton General Hospital, Hamilton, ON, Canada. A fluorescence polarization immunoassay was followed for the quantitative measurement of total L-Hcy. Gravimetrically prepared S-adenosyl-L-homocysteine in phosphate buffer $(2.5,5.0,10.0,20.0,50.0 \mu \mathrm{mol} / \mathrm{L} \mathrm{Hcy})$ and phosphate buffer ( $0 \mu \mathrm{mol} / \mathrm{L} \mathrm{Hcy})$ were used as calibrators. L-Hcy in processed human serum at known concentrations $(7.0 \mu \mathrm{mol} / \mathrm{L}, 12.5 \mu \mathrm{mol} / \mathrm{L}$ and $25.0 \mu \mathrm{mol} / \mathrm{L})$ were used as controls. The coefficients of variation were as follows: mean value $5.9 \mu \mathrm{mol} / \mathrm{L}(2.2 \% \mathrm{CV}$ within run, $5.2 \% \mathrm{CV}$ for total precision); mean value $10.8 \mu \mathrm{mol} / \mathrm{L}$ (1.9\% CV within run, $4.1 \% \mathrm{CV}$ for total precision); mean value $21.6 \mu \mathrm{mol} / \mathrm{L}$ (1.4\% CV within run, $3.7 \% \mathrm{CV}$ for total precision).

Niacin status was measured using the method of Jacobson and colleagues [22]. The coefficients of variation were as follows: NAD (10\% CV within and between runs); NADP (11\% CV within run and $14 \%$ CV between runs).

\section{Reference values}

Low $\mathrm{B}_{12}$ levels were defined as $<148 \mathrm{pmol} / \mathrm{L}$. Normal levels of $B_{12}$, but at the lower end (low normal), were classi- 
fied as 148 to $221 \mathrm{pmol} / \mathrm{L}$. Plasma PLP $\leq 30 \mathrm{nmol} / \mathrm{L}$ erythrocyte folate $<370 \mathrm{nmol} / \mathrm{L}$, niacin ratio (NAD/ $\mathrm{NADP}) \leq 1$, and Hcy $>13.3 \mu \mathrm{mol} / \mathrm{L}$ were indicative of low vitamin and elevated metabolite concentrations [22], respectively.

\section{Statistical analysis}

Summary statistics (mean, median, range, 95\% confidence interval) was determined using the original (nontransformed) variables. Parametric tests such as analysis of variance, regression models, and independent t-tests were performed on $\log$ (base 10) transformed variables to meet the assumption of normal distribution for the continuous variables (vitamin $\mathrm{B}_{12}$, vitamin $\mathrm{B}_{6}$, erythrocyte folate, niacin number (NAD/NADP*100) and Hcy). In determining the prevalence of vitamin supplementation within SMMSE or drug user groups chi-square analysis was conducted. Probablity values $<0.05$ were considered statistically significant. All analyses were done by using SPSS computer software (version 7.7).

\section{Results}

Table 1 lists the summary statistics and prevalence data for the vitamins and metabolites. The mean, median and $95 \%$ confidence intervals for vitamins $B_{12}$, erythrocyte folate, vitamin $\mathrm{B}_{6}$, and niacin number did not fall below their respective reference values of $148 \mathrm{pmol} / \mathrm{L}, 370$ $\mathrm{nmol} / \mathrm{L}, 30 \mathrm{nmol} / \mathrm{L}$, and 100, respectively. The $95 \%$ confidence interval of 12.1 to $14.9 \mu \mathrm{mol} / \mathrm{L}$ for Hcy went beyond its cut-off of $13.3 \mu \mathrm{mol} / \mathrm{L}$. Based on the established reference values, the prevalence of inadequate micronutrient status varied from $1-35 \%$ depending on the specific micronutrient examined (Table 1) and almost half of the subjects had elevated Hcy.

A multiple linear regression showed vitamin $B_{12}$ to be a significant Hcy predictor (See Table 5). Figure 1 shows the prevalence of Hcy elevations decreasing with increasing cobalamin levels from $60 \%$ for $\mathrm{B}_{12}<148 \mathrm{pmol} / \mathrm{L}$ to $46.2 \%$ for $\mathrm{B}_{12}$ between 148 and $221 \mathrm{pmol} / \mathrm{L}$ to $36.4 \%$ for $\mathrm{B}_{12}$ $>221 \mathrm{pmol} / \mathrm{L}$.

There was no significance when evaluating the main effect of vitamin status on SMMSE categorizations (marked, mild, normal). The prevalence of vitamin supplementation did not significantly differ between the marked, mild and normal SMMSE groups (See Table 2).

There were no significant differences in mean vitamin $B_{12}$ and Hcy levels between users and non-users of drug therapy (PPIs or H2-blockers): 304.6 (128.9) pmol/L and $15.2(9.2) \mu \mathrm{mol} / \mathrm{L}$ for users, respectively; 300.5 (182.7) $\mathrm{pmol} / \mathrm{L}$ and 12.8 (4.2) $\mu \mathrm{mol} / \mathrm{L}$ for non-users, respectively. Vitamin supplementation between groups did not significantly differ (See Table 3).
Table I: Summary statistics and prevalence data.

\begin{tabular}{|c|c|}
\hline & Total $(n=75)$ \\
\hline \multicolumn{2}{|c|}{ Vitamin $B_{12}(p m o l / L)$} \\
\hline Mean (SD) & $301.7(167.8)$ \\
\hline Median & 245.0 \\
\hline Range & $81.0-982.0$ \\
\hline $95 \% \mathrm{Cl}$ & $263.1-340.3$ \\
\hline$<148$ & $5(6.7 \%)$ \\
\hline$|48-22|$ & $26(34.7 \%)$ \\
\hline \multicolumn{2}{|c|}{ Erythrocyte folate (nmol/L) } \\
\hline Mean (SD) & 942.9 (367.9) \\
\hline Median & 868.0 \\
\hline Range & $316.0-2857.0$ \\
\hline $95 \% \mathrm{Cl}$ & $858.3-1027.5$ \\
\hline$<370$ & I (I.3\%) \\
\hline \multicolumn{2}{|c|}{ Vitamin $B_{6}(\mathrm{nmol} / \mathrm{L})$} \\
\hline Mean (SD) & $54.3(21.4)$ \\
\hline Median & 48.0 \\
\hline Range & $28.0-125.0$ \\
\hline $95 \% \mathrm{Cl}$ & $49.4-59.2$ \\
\hline$\leq 30$ & $4(5.3 \%)$ \\
\hline \multicolumn{2}{|l|}{ Hcy $(\mu \mathrm{mol} / \mathrm{L})$} \\
\hline Mean (SD) & $13.5(6.2)$ \\
\hline Median & 12.5 \\
\hline Range & $4.6-48.3$ \\
\hline $95 \% \mathrm{Cl}$ & $12.1-14.9$ \\
\hline$>13.3$ & 31 (4I.3\%) \\
\hline \multicolumn{2}{|l|}{ Niacin Number } \\
\hline Mean (SD) & $161.3(81.6)$ \\
\hline Median & 140.3 \\
\hline Range & $33.4-390.5$ \\
\hline $95 \% \mathrm{Cl}$ & $142.5-180.1$ \\
\hline Niacin Ratio $\leq \mathrm{I}$ & $20(26.7 \%)$ \\
\hline
\end{tabular}

Vitamin supplement users had higher mean vitamin $B_{12}$ $(\mathrm{p}<0.0001)$ and erythrocyte folate $(\mathrm{p}<0.05)$ concentrations and lower Hcy $(\mathrm{p}<0.01)$ than non-users (See Table 4). Although the folate status was significantly different, the mean value for both groups was above the reference value of $370 \mathrm{nmol} / \mathrm{L}$.

The prevalence of inadequate vitamin status was greater for those who were non-users of vitamin supplements compared to users. The group difference was significant for vitamin $\mathrm{B}_{12}$; among non-users 29/47 (61.7\%) had $\mathrm{B}_{12}$ $\leq 221 \mathrm{pmol} / \mathrm{L}$ compared to $2 / 28(7.1 \%)$ among users, $\mathrm{p}<$ 0.0001 (See Table 4).

A multiple linear regression model showed creatinine (p $<0.05)$ and vitamin $\mathrm{B}_{12}(\mathrm{p}<0.0001)$ as significant predictors of the criterion homocysteine. Among the other nonsignificant predictors were creatinine clearance, vitamin $\mathrm{B}_{6}$, erythrocyte folate, and age (See Table 5). The amount 


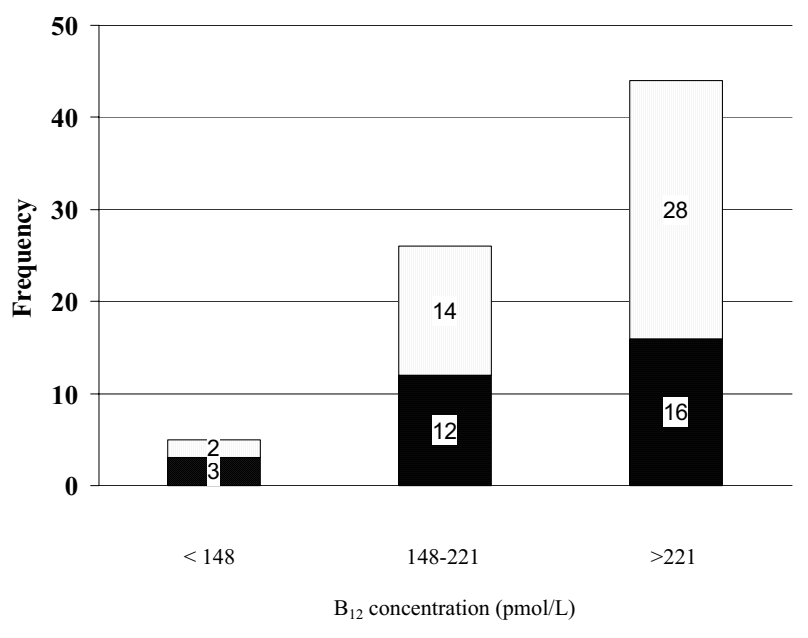

\section{Figure I}

Frequency of subjects with high or normal homocysteine levels as a function of serum $B_{12}$ levels. Darkly shaded area represents the subjects with elevated homocysteine $>13.3 \mu \mathrm{mol} /$ $\mathrm{L}$ while lightly shaded area represents subjects with homocysteine $\leq 13.3 \mu \mathrm{mol} / \mathrm{L}$ for the three vitamin $B_{12}$ intervals.

of variance of the criterion explained by the combined predictors was $41.2 \%$.

\section{Discussion}

The purpose of this study was to examine the frequency of $B$ vitamin deficiencies in a long-term care population in Ontario. Secondary objectives were to examine the relationship, if any, between specific markers of vitamin adequacy and: 1) the use of vitamin supplements, 2) the use of drugs that alter gastric acid secretion, 3) cognitive function as measured by performance on the Standardized Mini-Mental State Examination (SMMSE).

In this study, the prevalence of folate, vitamin $\mathrm{B}_{6}$ and niacin deficiency based on established reference values were 1.3\%, 5.3\% and 26.7\%, respectively. Among 177 institutionalized elderly (65-89 years) residing in Mexico, Ortega et al [23] found $6.6 \%$ to have erythrocyte folate $<360 \mathrm{nmol} / \mathrm{L}$. These authors also found a positive correlation between folate intake and erythrocyte folate $(r=0.28$, $\mathrm{p}<0.05)$. The fortification of many foods with folic acid in North America may explain the more optimal folate status in our subjects. In addition to dietary intake differences, geographical differences related to the prevalence of atrophic gastritis could also be considered. Atrophic gastritis creates a low acid environment, which is conducive to bacterial colonization and subsequent bacterial synthesis of absorbable folic acid [25].

The prevalence of vitamin $\mathrm{B}_{6} \leq 30 \mathrm{nmol} / \mathrm{L}$ at $5.3 \%$ was low when compared to Joosten et al [26] who reported $51 \%$ of
286 hospitalized patients (61-97 years) living in Belgium, Germany or the Netherlands, to have vitamin $\mathrm{B}_{6}<28.7$ nmol/L. Various factors could be considered to explain the difference in prevalence between the two studies including differences in sample size and variable consumption of nutrient rich foods. With respect to the latter, residents of Ontario may be better nourished because of habitual nutrient-rich food intake before and during hospitalization.

Niacin status has not been routinely examined in populations of younger or older adults. Thus there are few reports with which to compare our data. We report here a relatively high prevalence of low niacin status compared to the vitamins $\mathrm{B}_{6}$ and folate. The protective effect of niacin nutriture in carcinogenesis [27] prompted researchers towards developing a biomarker for niacin status. With the finding of NAD content in erythrocytes as a sensitive marker for niacin status in humans [28], niacin number (NAD/NADP*100) became a convenient way to evaluate the status of this micronutrient. A mean niacin number of 175 with a $95 \%$ confidence interval of 127 to 223 were found among free-living healthy adults and metabolic ward patients [24]. Fu et al [28] suggested a niacin number below 100 (or ratio of NAD/NADP of 1.0) may identify subjects at risk of niacin deficiency. Additionally, analysis of niacin status in different populations revealed $15-20 \%$ are niacin deficient $[29,30]$. Our study found $26.7 \%$ at risk of niacin deficiency; a prevalence worthy of greater attention.

Vitamin $\mathrm{B}_{12}$ deficiency is estimated to affect $10 \%$ to $15 \%$ of people over the age of 60 [12]. Serum cobalamin is most commonly used to diagnose deficiency although some have argued it has poor diagnostic efficiency [31]. Pennypacker et al [18] argued that serum vitamin $B_{12}$ was insensitive for screening since similar numbers of geriatric outpatients with low (<148 pmol/L) or low normal (148$221 \mathrm{pmol} / \mathrm{L})$ serum cobalamin had elevated metabolites (>21.3 $\mu \mathrm{mol} / \mathrm{L} \mathrm{Hcy}$ and $>376 \mathrm{nmol} / \mathrm{L} \mathrm{MMA}$ ), 62\% and $56 \%$ respectively, which fell with cobalamin treatment. Using identical low and low normal cobalamin references ranges, Yao et al [32] reported elevated metabolites ( $>16$ $\mu \mathrm{mol} / \mathrm{L} \mathrm{Hcy}$ and $>270 \mathrm{nmol} / \mathrm{L} \mathrm{MMA}$ ) in $80 \%$ and $33 \%$ of geriatric outpatients, respectively. For individuals 65 and older with serum cobalamin below $221 \mathrm{pmol} / \mathrm{L}$, the authors recommended analysis of Hcy and MMA, especially in those patients with unexplained hematological and neuropsychiatric disorders [32]. Using serum $B_{12}$ as an estimate of $B_{12}$ vitamin status, we found that fewer than $7 \%$ of the hospitalized patients had levels that fell below $148 \mathrm{pmol} / \mathrm{L}$ while 34.7\% had levels between 148 and $221 \mathrm{pmol} / \mathrm{L}$. Hcy elevations ( $>13.3 \mu \mathrm{mol} / \mathrm{L})$ within low (<148 pmol/L) and low normal (148-221 pmol/L) cobalamin ranges were $60 \%$ and $46.2 \%$, respectively. 
Table 2: Mean vitamin and metabolite levels according to SMMSE status.

\begin{tabular}{|c|c|c|c|c|}
\hline & \multicolumn{3}{|c|}{ SMMSE } & \multirow[b]{2}{*}{ p-value } \\
\hline & Marked $(0-20) n=44$ & Mild $(21-25) n=14$ & Normal $(26-30) n=9$ & \\
\hline \multicolumn{5}{|l|}{ Age (years) } \\
\hline Mean (SD) & $84.4(8.6)^{*}$ & $74.0(15.1)$ & $75.2(13.1)$ & $<0.01$ \\
\hline \multicolumn{5}{|l|}{ Vitamin $B_{12}(p m o l / L)$} \\
\hline Mean (SD) & $320.4(181.1)$ & $284.6(148.3)$ & $256.9(99.4)$ & n.s. \\
\hline \multicolumn{5}{|c|}{ Erythrocyte folate (nmol/L) } \\
\hline Mean (SD) & $972.2(286.5)$ & $730.9(117.9)$ & $992.7(471.2)$ & n.s. \\
\hline \multicolumn{5}{|l|}{ Vitamin $B_{6}(\mathrm{nmol} / \mathrm{L})$} \\
\hline Mean (SD) & $54.0(20.5)$ & $58.1(28.4)$ & $56.0(23.6)$ & n.s. \\
\hline \multicolumn{5}{|l|}{ Hcy ( $\mu \mathrm{mol} / \mathrm{L})$} \\
\hline Mean (SD) & $13.9(6.8)$ & $10.4(3.0)$ & |4.| (5.4) & n.s. \\
\hline \multicolumn{5}{|l|}{ Niacin Number } \\
\hline Mean (SD) & $166.5(82.1)$ & $150.2(58.8)$ & $147.3(66.1)$ & n.s. \\
\hline \multicolumn{5}{|c|}{ Vitamin Supplementation } \\
\hline n (\%) within each group & $17(38.6 \%)$ & $5(35.7 \%)$ & $4(44.4 \%)$ & n.s. \\
\hline
\end{tabular}

$* p<0.01$ for comparison with mild group

n.s. - not significantly different

Homocysteine and methylmalonic acid (MMA) - both products of reactions requiring cobalamin - carry greater diagnostic utility [31], although the cost of associated assays may hamper their widespread use [31].

Among older people, increased medication use and gastrointestinal changes are factors that affect micronutrient absorption. For vitamins such as cobalamin, mechanisms leading to potential deficiency due to malabsorption include: 1) Inadequate cleavage of protein-bound $B_{12}$ due to hypoacidity (hypochlorhydria/achlorhydria), 2) Decreased secretion of intrinsic factor (a vitamin $\mathrm{B}_{12}$ carrier molecule), and 3) Gastric bacterial overgrowth (particularly Escherichia coli which absorb vitamin $\mathrm{B}_{12}$ ). The contributing factors to these gastrointestinal changes are pernicious anemia and Helicobacter pylori infection, associated with type A and type $\mathrm{B}$ atrophic gastritis, respectively [12]. Atrophic gastritis, bacterial overgrowth and medication use (proton pump inhibitors or H2-blockers) are possible explanations. However, the mean $\mathrm{B}_{12}$ (304.6 and $300.5 \mathrm{pmol} / \mathrm{L}$ ) and Hcy (15.2 and $12.8 \mu \mathrm{mol} / \mathrm{L}) \mathrm{lev}$ els did not significantly vary between users and non-users of drug therapy, respectively. It is thus unlikely these medications would have induced low cobalamin and elevated homocysteine states. Two factors should however be acknowledged in evaluating the potential effect of gastric acid lowering medications on vitamin $\mathrm{B}_{12}$ absorption: 1 ) type of drug (PPI or H2-blocker) and 2) duration of medication use. In a study comparing omeprazole (a PPI) with H2-blocker therapy in Zollinger-Ellison syndrome patients [33], those treated with omeprazole $(n=111$; mean duration of 4.5 years) had significantly lower serum $B_{12}$ levels than those treated with H2-blockers $(n=20$; mean duration of 10 years). Omeprazole treatment reduced acid secretion to significantly lower levels than H2-blockers. Sustained hypochlorhydria or achlorhydria,

Table 3: A comparison of vitamin $B_{12}$, Hcy and vitamin supplementation between users and non-users of drug therapy (proton-pump inhibitors and $\mathrm{H}$ 2-blockers).

\begin{tabular}{|c|c|c|c|}
\hline & \multicolumn{2}{|c|}{ Drug Therapy } & \multirow[b]{2}{*}{ p-value } \\
\hline & User $(n=22)$ & Non-user $(n=53)$ & \\
\hline \multicolumn{4}{|l|}{ Vitamin $B_{12}(p m o l / L)$} \\
\hline Mean (SD) & $304.6(128.9)$ & $300.5(182.7)$ & n.s. \\
\hline \multicolumn{4}{|l|}{ Hcy ( $\mu \mathrm{mol} / \mathrm{L})$} \\
\hline Mean (SD) & $15.2(9.2)$ & $12.8(4.2)$ & n.s. \\
\hline \multicolumn{4}{|l|}{ Vitamin Supplementation } \\
\hline $\mathrm{n}(\%)$ within each group & II (50.0\%) & 17 (32.0\%) & n.s. \\
\hline
\end{tabular}

n.s. - not significantly different 
Table 4: Summary statistics and prevalence data for users and non-users of vitamin supplementation.

\begin{tabular}{|c|c|c|c|}
\hline & \multicolumn{2}{|c|}{ Vitamin Supplementation } & \multirow[b]{2}{*}{ p-value } \\
\hline & Users $(n=28)$ & Non-users $(n=47)$ & \\
\hline \multicolumn{4}{|c|}{ Vitamin $B_{12}(p m o l / L)$} \\
\hline Mean (SD) & $423.6(191.6)$ & $229.1(96.7)$ & $P<0.0001$ \\
\hline$\leq 221$ & $2(7.1 \%)$ & $29(61.7 \%)$ & $p<0.0001$ \\
\hline \multicolumn{4}{|c|}{ Erythrocyte folate (nmol/L) } \\
\hline Mean (SD) & $1043.6(345.8)$ & $882.9(371.1)$ & $p<0.05$ \\
\hline$<370$ & 0 & I (2.1\%) & n.s. \\
\hline \multicolumn{4}{|c|}{ Vitamin $B_{6}(\mathrm{nmol} / \mathrm{L})$} \\
\hline Mean (SD) & $54.6(25.3)$ & $54.1(19.1)$ & n.s. \\
\hline$\leq 30$ & $2(7.1 \%)$ & $2(4.3 \%)$ & n.s. \\
\hline \multicolumn{4}{|l|}{ Hcy ( $\mu \mathrm{mol} / \mathrm{L})$} \\
\hline Mean (SD) & $12.0(4.9)$ & $14.4(6.7)$ & $p<0.01$ \\
\hline$>13.3$ & $8(28.6 \%)$ & $23(48.9 \%)$ & n.s. \\
\hline \multicolumn{4}{|l|}{ Niacin } \\
\hline Mean (SD) & $177.7(79.9)$ & $151.5(81.8)$ & n.s. \\
\hline Niacin Ratio $\leq 1$ & $4(14.3 \%)$ & $16(34.0 \%)$ & n.s. \\
\hline
\end{tabular}

n.s. not significantly different

primarily occurring in those treated with omeprazole, was the only factor associated with reduced serum $\mathrm{B}_{12}$ levels. To explain this difference researchers have noted that PPIs cause prolonged, profound hypochlorhydria [34] whereas the effect of $\mathrm{H} 2$ blockers is short lived - a transient hypochlorhydria [35]. Among users of drug therapy $(\mathrm{n}=$ 22 ) in our study population, the majority used H2-blockers $(16 / 22$ or $73 \%)$ versus PPIs $(6 / 22$ or $27 \%)$. Duration of medication use was not considered in our study. Studies have shown that prolonged treatment with PPIs ( 3.5 years) [36] or H2-blockers [37] is needed to develop low cobalamin levels. The potential for acute medication use and the preferred administration of H2-blockers over PPIs may thus be contributing to the lack of effect of these medications on vitamin $B_{12}$ and Hcy levels. Alternatively, it is possible that the small number of subjects, particularly in the drug-user category, may have obscured differences between the two groups in our study. In future work it would be valuable to have a larger number of drug using subjects for comparison.

Table 5: Significance of homocysteine predictors from multiple linear regression.

\begin{tabular}{lc}
\hline \multicolumn{1}{c}{ Predictor } & p-value \\
\hline Vitamin $\mathrm{B}_{12}(\mathrm{pmol} / \mathrm{L})$ & $\mathrm{P}<0.000 \mathrm{I}$ \\
Erythrocyte folate $(\mathrm{nmol} / \mathrm{L})$ & n.s. \\
Vitamin $\mathrm{B}_{6}(\mathrm{nmol} / \mathrm{L})$ & n.s. \\
Age $($ years $)$ & n.s. \\
Creatinine $(\mu \mathrm{mol} / \mathrm{L})$ & $\mathrm{P}<0.05$ \\
Creatinine clearance $(\mathrm{ml} / \mathrm{min})$ & n.s. \\
\hline
\end{tabular}

n.s. - not significantly different
Joosten et al [25] estimated 51\% of 286 hospitalized elderly to have Hcy elevated $>13.9 \mu \mathrm{mol} / \mathrm{L}$. The only exclusion criteria for this group of subjects were the presence of life-threatening disease. Otherwise, subjects with common geriatric diseases (vascular disease, dementia, diabetes mellitus, osteoporosis, osteoarthritis) were included. Among the factors that significantly correlated with homocysteine were vitamin $\mathrm{B}_{12}(\mathrm{r}=-0.27, \mathrm{p}=0.0001)$, serum folate $(\mathrm{r}=-0.38, \mathrm{p}=0.0001)$, and creatinine clearance $(\mathrm{r}=-0.44, \mathrm{p}<0.001)$ [24]. Within our sample population, a $41.3 \%$ prevalence of Hcy $>13.3 \mu \mathrm{mol} / \mathrm{L}$ was found, the only significant predictors being vitamin $B_{12}(p$ $<0.0001)$ and creatinine $(\mathrm{p}<0.05)$. If a relationship exists between renal insufficiency and Hcy, it would be more meaningful and reliable to use creatinine clearance over creatinine as a marker of kidney function in older people. This is because body mass declines with age and creatinine clearance is determined irrespective of muscle mass. Creatinine clearance was not a significant predictor of Hcy in our study, implying a lack of effect of renal function on Hcy levels. The significant relationship we found between creatinine and Hcy is in line with what others have observed [38-40].

The dependence of Hcy on vitamin $\mathrm{B}_{12}$, vitamin $\mathrm{B}_{6}$ and folate as coenzymes in its metabolism explains the significance of B vitamins in cases of elevated Hcy. In fact, Selhub et al found inadequate plasma concentrations of one or more B vitamins (plasma folate, vitamin $B_{12}$, vitamin $B_{6}$ ) to contribute to $67 \%$ of high homocysteine cases ( $>14$ $\mu \mathrm{mol} / \mathrm{L}$ ) in an elderly population [40]. As mentioned earlier, of the three $B$ vitamins, only vitamin $B_{12}$ was a significant predictor of Hcy in our study. Although vitamin $B_{6}$ has shown weaker associations with Hcy, we expected 
folate to be a significant predictor [40]. A possibility for folate's non-significance is our selection of erythrocyte folate over serum folate as a status indicator. Koehler et al [41] showed serum Hcy to be negatively correlated with all three folate status indicators (serum, erythrocyte, and dietary intake). However, the authors commented that Hcy corresponded best to short-term folate status as measured by serum folate.

With respect to vitamin $B_{6}$, evidence also exists to suggest a lack of significance between Hcy and vitamin $\mathrm{B}_{6}$. Miller et al [42] found no elevation in fasting plasma homocysteine concentrations in studies with animals and humans administered vitamin $\mathrm{B}_{6}$ deficient diets. Further, Ubbink et al, showed a non-significant effect of a daily pyridoxine dose on plasma homocysteine concentrations. This was in contrast to folic acid and vitamin $\mathrm{B}_{12}$ supplementation, each of which significantly lowered elevated Hcy [43].

Hcy concentrations increase with age [44-46] and the majority of high Hcy cases in an older population can be attributed to vitamin status [40]. A possible explanation for the association between age and Hcy is an age-related decline in enzymes involved in Hcy metabolism [46]. Similar to Koehler et al [41] (100 free living elderly, 68 to 96 years) who found vitamin supplement users to have a significantly better micronutrient profile: 391 vs 292 $\mathrm{pmol} / \mathrm{L}$ (vitamin $\mathrm{B}_{12}$ ), 1626 vs $1036 \mathrm{nmol} / \mathrm{L}$ (erythrocyte folate), and $9.5 \mathrm{vs} 11.2 \mu \mathrm{mol} / \mathrm{L}$ (Hcy), we found significantly improved cobalamin ( $\mathrm{p}<0.0001)$, erythrocyte folate ( $\mathrm{p}<0.05)$, and Hcy ( $<<0.01)$ among supplement users. Additionally, there was a significantly lower prevalence of vitamin $B_{12}$ levels $\leq 221 \mathrm{pmol} / \mathrm{L}$ among supplement users. The composition of the multivitamin in our study included $3 \mu \mathrm{g}$ of vitamin $B_{12}$ and $1 \mathrm{mg}$ of vitamin $B_{6}$. Some patients were also given an intramuscular cobalamin injection of $1000 \mu \mathrm{g}$. Considering the weaker effect of vitamin $\mathrm{B}_{6}$ supplementation on Hcy levels [43] and the absence of folic acid in the multivitamin preparation, which has been shown to most effectively reduce Hcy $[42,22]$, it may be that cobalamin was responsible for Hcy lowering in our study, reflecting an intracellular cobalamin deficiency. Rasmussen et al showed a significant average Hcy decrease with cobalamin supplementation alone [46].

Up to $62 \%$ of institutionalized older people have dementia [48], and in one study undernutrition was reported in $45.5 \%$ of a long-term care population $(\mathrm{n}=200)$ [49]. A multitude of factors - physical, psychological, social and cultural - act on an aged population to reduce dietary intake and alter nutrient metabolism [50]. This demographic is thus at risk of malnutrition, a factor associated with increased morbidity and morality [50]. A study by
Litchford et al [51] showed how cognitive dysfunction further exacerbates the already vulnerable nutritional state of an older population. Patients with senile dementia of the Alzheimer's type had lower food intakes and higher energy expenditures compared to cognitively normal elders. A lack of macronutrient repletion in these dementia patients, compounded by a potentially increased micronutrient need (due to alterations in metabolic pathways) could accelerate cognitive decline.

A number of conditions can cause dementia, an aetiology related to nutrition being one of many possibilities. Within our study population there was no association between vitamin status and MMSE category (marked, mild, normal). Whether poor dietary practices lead to cognitive decline or that cognitive decline affects nutritional status, perhaps mediated by metabolic alterations has not been determined. Nevertheless, because poor dietary practices have been shown to influence memory and learning suggests the brain's vulnerability to diet.

To date, there have been no studies of a similar cross-sectional nature conducted on a long-term care population in Ontario. Assessing the prevalence of inadequate vitamin or metabolite status is a starting point for understanding the needs of an aging population and for evaluating the usefulness of therapeutic interventions related to improving vitamin intake. Based on our findings and those of others, we recommend that clinical intervention trials be initiated amongst older populations, both in and out of the hospital setting, to determine the usefulness of this strategy in combating the high frequency of nutrient deficiencies in this population.

\section{Competing interests}

The author(s) declare that they have no competing interests.

\section{Authors' contributions}

Lina Paulionis carried out the recruitment of subjects, applied the MMSE, carried out biochemical analysis and all data analysis and assisted in writing the final manuscript. Sheri-Lynn Kane provided advice as Geriatrician for the study and coordinated all activities at St. Joseph's Hospital and Home, including preparation and presentation of the study for funding and for ethics approval. Dr. Kane also provided expertise in setting cut-off values and final formatting of the manuscript. Kelly Meckling, conceived of the idea for the study, recruited the student and physician to coordinate the study and provided research support and advice throughout the project. Together with Ms. Paulionis they selected the appropriate biochemical and statistical measures to be implemented. Dr. Meckling also worked with the other authors on the final version of the manuscript. 


\section{Acknowledgements}

This work was supported by a research grant from St. Joseph's Hospital and Home, Guelph Ontario. It was also supported in part by the Natural Sciences Engineering Research Council of Canada.

\section{References}

I. Goodwin JS, Goodwin JM, Garry P: Association between nutritional status and cognitive functioning in a healthy elde rly population. JAMA 1983, 249:2917-292I.

2. Ortega RM, Requejo AM, Andres P, Lopez-Sobaler AM, Quintas ME, Redondo $M R$, Navia $B$, Rivas $T$ : Dietary intake and cognitive function in a group of elderly people. Am J Clin Nutr 1997, 66:803-809.

3. La Rue A, Koehler KM, Wayne SJ, Chiulli SJ, Haaland KY, Garry PJ: Nutritional status and cognitive functioning in a normally aging sample: a 6-y reassessment. Am J Clin Nutr 1997, 65:20-29.

4. Greenwood CE, Winocur G: Decline in cognitive function with aging: impact of diet. Mature Medicine 1999:205-209.

5. Raskind M: Nutrition and cognitive function in the elderly. JAMA 1983, 249:2939-2940.

6. Bell IR, Edman JS, Miller J, Hebben N, Linn RT, Ray D, Kayne HL: Relationship of normal serum vitamin $B / 2$ and folate levels to cognitive test performance in subtypes of geriatric major depression. J Geriatr Psychiatry Neurol 1990, 3:98-105.

7. Driskell JA: Vitamin B6 requirements of humans. Nutr Res 1994 , 14:293-324

8. Riggs KM, Spiro A 3rd, Tucker K, Rush D: Relations of vitamin B I 2, vitamin B6, folate, and homocysteine to cognitive performance in the Normative Aging Study. Am J Clin Nutr 1996, 63:306-314.

9. Clarke R, Smith AD, Jobst KA, Refsum H, Sutton L, Ueland PM: Folate, vitamin $B \mid 2$ and serum total homocysteine levels in confirmed Alzheimer disease. Arch Neurol 1998, 55: |449-| 455.

10. McCaddon A, Davies G, Hudson P, Tandy S, Cattell H: Total serum homocysteine in senile dementia of Alzheimer Type. Int J Geriat Psychiatry 1998, 13:235-239.

II. Kasper H: Vitamin Absorption in the Elderly. Int J Vitam Nutr Res 1999, 69:169-172.

12. Baik HW, Russell RM: Vitamin B/2 deficiency in the elderly. Annu Rev Nutr 1999, 19:357-377.

13. Van den Berg $\mathrm{H}$ : Vitamin B6 status and requirements in older adults. Brit J Nutr 1999, 8 I: I75-176.

14. Rose CS, Gyorgy P, Butler M, Andres R, Norris AH, Shock NW, Tobin J, Brin M, Spiegel H: Age differences in vitamin B6 status of 617 men. Am J Clin Nutr 1976, 29:847-853.

15. Krasinski SD, Russell RM, Samloff IM, Jacob RA, Dallal GE, McGandy RB, Hartz SC: Fundic atrophic gastritis in an elderly population: effect on hemoglobin and several serum nutritional indicators. J Am Geriatr Soc 1986, 34:S00-S06.

16. Bradford GS, Taylor CT: Omeprazole and Vitamin B/2 deficiency. Annals Pharmacotherapy 1999, 33:641-643.

17. Russell RM: The aging process as a modifier of metabolism. Am J Clin Nutr 2000, 72(suppl):529S-532S.

18. Pennypacker LC, Allen RH, Kelly JP, Matthews LM, Grigsby J, Kaye K, Lindenbaum J, Stabler SP: High prevalence of cobalamin deficiency in elderly outpatients. J Am Geriatr Soc 1992, 40: II97-1 204.

19. Selhub J: Homocysteine metabolism. Annu Rev Nutr 1999, 1 9:217-246.

20. Diaz-Arrastia R: Homocysteine and neurologic disease. Arch Neurol 2000, 57:|422-1428.

21. Molloy W: Standardized Mini-Mental State Examination. New Grange Press, Canada; 1999.

22. Joosten E, Lesaffre R, Riezler R: Are different reference intervals for methylmalonic acid and total homocysteine necessary in elderly people. Eur J Haematol 1996, 57:222-226.

23. Ortega RM, Manas LR, Andres P, Gaspar MJ, Agudo FR, Jimenez A, Pascual T: Functional and psychic deterioration in elderly people may be aggravated by folate deficiency. J Nutr 1996, | 26: 1992-1999.

24. Jacobson EL, Jacobson MK: Tissue NAD as a biochemical measure of niacin status in humans. Methods Enzymol 1997, 280:221-230.

25. Camilo E, Zimmerman J, Mason JB, Golner B, Russell R, Selhub J, Rosenberg $\mathrm{IH}$ : Folate synthesized by bacteria in the human upper small intestine is assimilated by the host. Gastroenterol 1996, I 1 0:991-998.

26. Joosten E, van den Berg A, Riezler R, Naurath HJ, Lindenbaum J, Stabler SP, Allen RH: Metabolic evidence that deficiencies of vitamin BI2 (cobalamin), folate, and vitamin B6 occur commonly in elderly people. Am / Clin Nutr 1993, 58:468-476.

27. Jacobson EL, Shieh WM, Huang AC: Mapping the role of NAD metabolism in prevention and treatment of carcinogenesis. Mol Cell Biochem 1999, 193:69-74.

28. Fu CS, Swendseid ME, Jacob RA, McKee RW: Biochemical markers for assessment of niacin status in young men: levels of erythrocyte niacin coenzymes and plasma tryptophan. J Nutr 1989, I I 9:1949-1955.

29. Knebl JA, Jacobson EL: Assessment of niacin status in an elderly population. The Gerontologist 1992, 32:247A.

30. Jacobson E: Niacin deficiency and cancer in women. J Am Coll Nutr 1993, 1 2:412-416.

31. Holleland G, Schneede J, Ueland PM, Lund PK, Refsum H, Sandberg S: Cobalamin deficiency in general practice. Assessment of the diagnostic utility and cost-benefit analysis of methylmalonic acid determination in relation to current diagnostic strategies. Clin Chem 1999, 45:189-198.

32. Yao Y, Yao SL, Yao SS, Yao G, Lou W: Prevalence of vitamin B I 2 deficiency among geriatric outpatients. J Fam Pract 1992, 35:524-528.

33. Termanini B, Gibril F, Sutliff VE, Yu F, Venzon DJ, Jensen RT: Effect of long-term gastric acid suppressive therapy on serum vitamin B 2 levels in patients with Zollinger-Ellison syndrome. Am J Med 1998, 1 04:422-430.

34. Clissold SP, Campoli-Richards DM: Omeprazole: a preliminary review of its pharmacodynamic and pharmacokinetic properties and therapeutic potential on peptic ulcer disease and Zollinger-Ellison syndrome. Drugs 1986, 32:I5-47.

35. Lanzon-Miller S, Pounder RE, Hamilton MR, Ball S, Chronos NA, Raymond $F$, Olausson $M$, Cederberg $C$ : Twenty-four-hour intragastric acidity and plasma gastrin concentration before and during treatment with either ranitidine or omeprazole. Aliment Pharmacol Ther 1987, I:239-25I.

36. Koop H: Metabolic consequences of long-term inhibition of acid secretion by omeprazole. Aliment Pharmacol Ther 1992, 6:399-406.

37. Force RW, Nahata MC: Effect of histamine H2-receptor antagonists on vitamin BI2 absorption. Ann Pharmacother 1992, 26: $1283-1286$.

38. Carmel R, Green R, Jacobsen DW, Rasmussen K, Florea M, Azen C: Serum cobalamin, homocysteine, and methylmalonic acid concentrations in a multiethnic elderly population: ethnic and sex differences in cobalamin and metabolite abnormalities. Am J Clin Nutr 1999, 70:904-910.

39. Lindenbaum J, Rosenberg IH, Wilson PW, Stabler SP, Allen RH: Prevalence of cobalamin deficiency in the Framingham elderly population. Am J Clin Nutr 1994, 60:2-II.

40. Selhub J, Jacques PF, Wilson PW, Rush D, Rosenberg IH: Vitamin status and intake as primary determinants of homocysteinemia in an elderly population. JAMA 1993, 270:2693-2698.

4I. Koehler KM, Romero LJ, Stauber PM, Pareo-Tubbeh SL, Liang HC, Baumgartner RN, Garry PJ, Allen RH, Stabler SP: Vitamin supplementation and other variables affecting serum homocysteine and methylmalonic acid concentrations in elderly men and women. J Am Coll Nutr 1996, I 5:364-376.

42. Miller JW, Ribaya-Mercado JD, Russell RM, Shepard DC, Morrow FD, Cochary EF, Sadowski JA, Gershoff SN, Selhub J: Effect of vitamin B6-deficiency on fasting plasma homocysteine concentrations. Am J Clin Nutr 1992, 55: I I 54- I I60.

43. Ubbink JB, Vermaak WJ, van der Merwe A, Becker PJ, Delport R, Potgieter HC: Vitamin requirements for the treatment of hyperhomocysteinemia in humans. I Nutr 1994, I 24:1927-1933.

44. Nygard O, Vollset SE, Refsum H, Stensvold I, Tverdal A, Nordrehaug JE, Ueland M, Kvale G: Total plasma homocysteine and cardiovascular risk profile: The Hordaland Homocysteine Study. JAMA 1995, 274:I526-I533.

45. Kant AK, Moser-Veillon PB, Reynolds RD: Effect of age on changes in plasma, erythrocyte, and urinary $B 6$ vitamers after an oral vitamin B6 load. Am J Clin Nutr I 988, 48: I 284- I 290.

46. Rasmussen K, Moller J, Lyngbak M, Pedersen AM, Dybkjaer L: Ageand gender-specific reference intervals for total homo- 
cysteine and methylmalonic acid in plasma before and after vitamin supplementation. Clin Chem 1996, 42:630-636.

47. Gartler SM, Hornug SK, Motulsky AG: Effect of chronologic age on induction of cystathionine synthase, uroporphyrinogen I synthase, and glucose-6-phosphate dehydrogenase activities in lymphocytes. Proc Natl Acad Sci USA 198I, 78:1916-1919.

48. Matthews FE, Dening T: Prevalence of dementia in institutional care. Lancet 2002, 360:225-226.

49. Keller $\mathrm{HH}$ : Malnutrition in institutionalized elderly: how and why? J Am Geriatr Soc 1993, 41:1212-1218.

50. Clarke DM, Wahlqvist ML, Strauss BJG: Undereating and undernutrition in old age: integrating bio-psychosocial aspects. Age and Ageing 1998, 27:527-534.

51. Litchford MD, Wakefield LM: Nutrient intakes and energy expenditures of residents with senile dementia of the Alzheimer's type. J Am Diet Assoc 1987, 87:21 I-213.

\section{Pre-publication history}

The pre-publication history for this paper can be accessed here:

http://www.biomedcentral.com/1471-2318/5/16/prepub

Publish with Biomed Central and every scientist can read your work free of charge

"BioMed Central will be the most significant development for disseminating the results of biomedical research in our lifetime. "

Sir Paul Nurse, Cancer Research UK

Your research papers will be:

- available free of charge to the entire biomedical community

- peer reviewed and published immediately upon acceptance

- cited in PubMed and archived on PubMed Central

- yours - you keep the copyright

Submit your manuscript here:

http://www.biomedcentral.com/info/publishing_adv.asp 